\title{
A Multicriteria Decision Tool for Prioritizing Gas Monetization Projects in Nigeria
}

\author{
${ }^{1}$ Omo-Irabor Omoleomo O., ${ }^{2}$ Omo-Irabor Imuetiyan E., ${ }^{3}$ Ogala Jude E., ${ }^{4}$ Emudianughe, Juliet E. \\ ${ }^{1,4}$ Department of Earth Sciences, Federal University of Petroleum Resources, Effurun, Nigeria \\ ${ }^{2}$ Department of Road Transport Operations, Edo State Ministry of Infrastructure, Benin City, Nigeria \\ ${ }^{3}$ Department of Geology, Delta State University, Abraka, Nigeria
}

\begin{abstract}
The sharp fall in the trading price of crude oil lately, is gradually leading to a paradigm shift from the dependence on oil as Nigeria's major source of Gross Domestic Product (GDP). Natural gas is rapidly becoming a global energy product and serves as a substitute for oil, being a cleaner burning conventional fuel, producing lower levels of greenhouse gas emissions than the heavier hydrocarbon fuels. Nigeria is the largest holder of proven natural gas reserves in Africa and the ninth-largest holder globally. Nigeria flares a significant portion of its gross natural gas production, thereby leading to a waste of this non-renewable resource. Consequently, there is the need to diversify in areas such as monetizing gas projects. This will reduce gas flaring, increase revenue and increase gas conversion while promoting a sustainable hydrocarbon business in a prolonged, low and fluctuating oil price regime. This paper presents the analytical hierarchy process (AHP) decision tool to prioritize gas projects taking cognizance of technical, economic, environmental and health and safety factors of the proposed projects. Based on the findings, the decision tool is able to identify and prioritize gas projects to enhance other forms of revenue generation in Nigeria.
\end{abstract}

Keywords: Gas Monetization Projects, Natural Gas, Analytical Hierarchy Process (AHP), Decision Tool, Stakeholders.

\section{INTRODUCTION}

Although oil is still the main source of energy especially for industrial and transport purposes, its gradual depletion coupled with the attendant problem of greenhouse gas emission is causing a shift to other sources of energy. After the world's oil crisis in the 1970s, there became the realization for there to be a gradual shift on the dependence of Natural gas is steadily taking centre stage as a clean alternative source of energy. According to Marcilly [1], proven world gas reserves increased considerably, and on January 1, 2000, they exceeded oil reserves in Gtoe, without counting the enormous methane reserves trapped in the form of hydrates at the bottom of the oceans.
Nigeria holds the tenth largest natural gas reserve in the world with more than 5.2 trillion cubic meters [2] and the first in Africa, becoming a major player not only in the oil sector but also in the gas market globally. It is hoped that natural gas will be an additional source of to the foreign exchange earnings alongside oil which currently accounts for over 90 percent. Natural gas occurs in almost equal proportions as associated and non-associated (Table 1). The associated gas is usually extracted with crude oil as byproduct and are vented or flared depending on the quantity.

Table 1: Oil and gas reserves in Nigeria

\begin{tabular}{|l|l|l|l|l|}
\hline \multirow{2}{*}{ Year } & \multicolumn{4}{|l|}{ Natural Gas Reserves (TCF) } \\
\cline { 2 - 5 } & Oil Reserves MMbbls & $\begin{array}{l}\text { Associated Gas } \\
\text { (AG) }\end{array}$ & $\begin{array}{l}\text { Non Associated Gas } \\
\text { (NAG) }\end{array}$ & Total Gas \\
\hline 2010 & $36,532.07$ & 92.95 & 89.87 & 182.82 \\
\hline 2011 & $36,247.41$ & 92.9 & 90.53 & 183.43 \\
\hline 2012 & $37,139.10$ & 89.73 & 92.53 & 182.26 \\
\hline 2013 & $37,070.83$ & 89.65 & 92.3 & 181.95 \\
\hline 2014 & $37,448.00$ & 90.09 & 97.9 & 188.00 \\
\hline 2015 & $37,062.06$ & 97.21 & 94.86 & 192.07 \\
\hline
\end{tabular}

Source: Department of Petroleum Resources (DPR), 2015 Nigerian Oil \& Gas Industry Annual Report

It is estimated that Nigeria loses about $\$ 1$ billion of revenue to the flaring of gas; this approximates 700 million standard cubic feet per day (mm-scf/d). Until recently, some of the associated natural gas is re-injected into reservoirs to increase secondary recovery of oil. In a bid to reduce gas flaring most companies are now beginnings to get interested in venturing into gas-based projects.

Gas flaring has several implications for the environment. Flaring is known to cause heat radiation and thermal conduction into the immediate environment, lead to the production of toxic gases during combustion, produce high noise levels, generate and disperse particulate and other gases such as carbon dioxide (CO2) and nitrous oxides (NOx) into the atmosphere [3].

The factors that favor the production of different natural gas products are dependent of market demand \& supply and pricing. Under the gas to products scheme, there are four possibilities. 
ISSN (online): 2581-3048

Volume 4, Issue 8, pp 20-24, August-2020

The monetization of natural gas options is varied and poses risks and challenges to decision makers with limited expenditure. Companies are more concerned with the huge return on projects with quick profit. In terms of energy generation, Nigeria has kick started the 7 Critical Gas Development Projects (7CGDP) to distribute approximately 3.4 billion standard cubic feet of gas per day (bscfd). According to NNPC the 7CGDP include:

- Development of the 4.3 trillion cubic feet (TCF) Assa North/Ohaji South field;

- Development of the 6.4 TCF Unitized Gas fields (Samabri-Biseni, Akri-Oguta, Ubie-Oshi and AfuoOgbainbri);

- Development of 7.0 TCF NPDC's OML 26, 30 \& 42.

- development of 2.2 TCF Shell Petroleum Development Company (SPDC) JV Gas Supply to Brass Fertilizer Company;

- Cluster development of 5.0 TCF Oil Mining Lease OML, 13 to support the expansion of Seven Energy Uquo Gas Plant;

- And the cluster development of 10 TCF Okpokunou/Tuomo West (OML 35\& 62).

There is no evidence in the literature to indicate selection process used in arriving at the above mentioned projects.

The application of MCDM tools for the prioritizing of projects has be carried out by several authors such as Farkas [4] for civil engineering projects and Gomes, et al.[5]

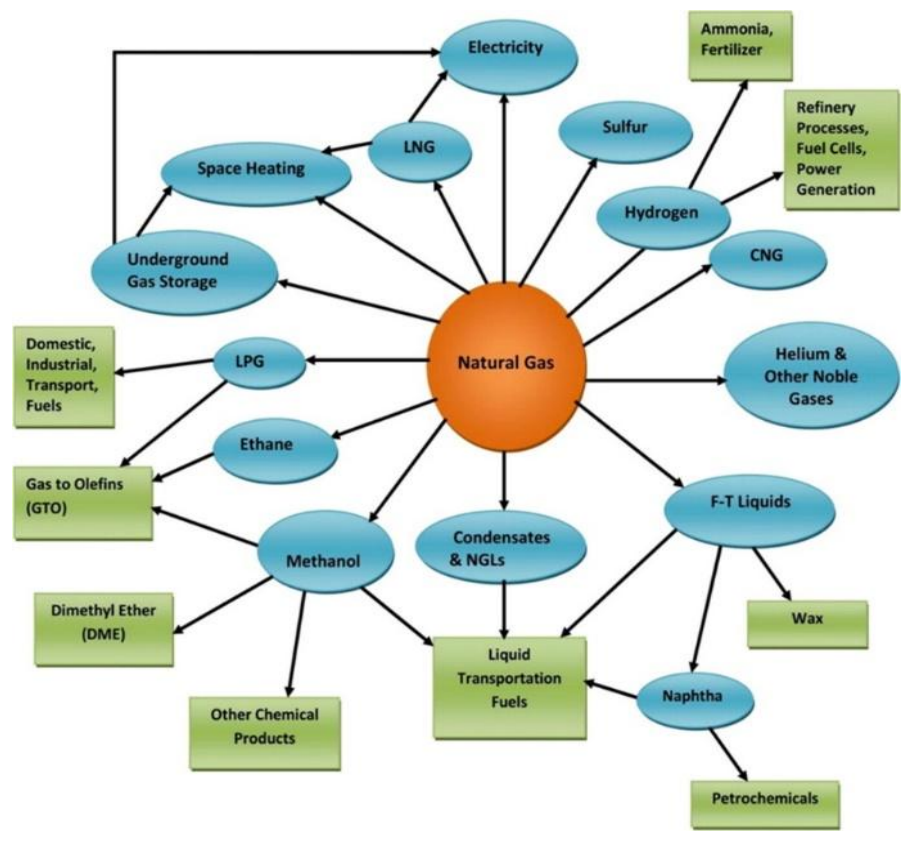

Figure 1: Uses of Natural Gas[6]
https://doi.org/10.47001/IRJIET/2020.408004

\section{METHODOLOGY}

The approach applied in the selection of the best option gas monetization projects is presented in Figure 2. There are several complexities involved in decision making due to uncertainty. There are usually two types of comparisons that can be made; relative and absolute. In relative comparison, alternatives are compared in pairs according to a common attribute, whist absolute comparison; alternatives are compared with a standard or baseline.

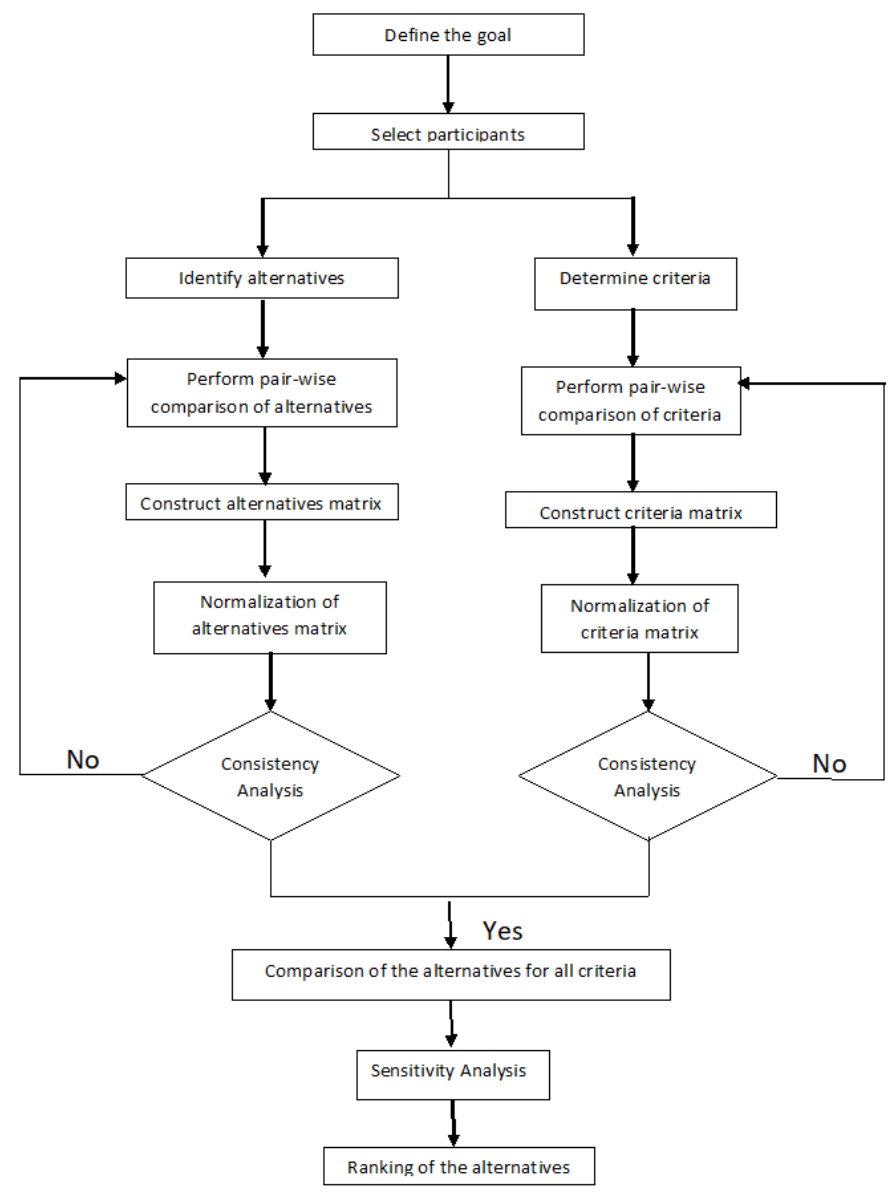

Figure 2: Flowchart of process for ranking projects

\subsection{Analytical Hierarchy Process}

Saaty[7], developed the Analytical Hierarchy Process (AHP) for formulating and analyzing decisions and has the ability of transforming qualitative judgements into numerical quantities. The use of AHP in decision problem solving is based upon the construction of a number of pair-wise comparisons that relates the criteria among themselves to determine the eigenvector weights from ratio scales. The typical AHP scale varies from 1 to 9 as shown in Table 2 According to Farkas[4], the scale used in AHP has been validated for effectiveness by numerous applications in a variety of professional fields of interest. 
ISSN (online): 2581-3048

Volume 4, Issue 8, pp 20-24, August-2020

Table 2: Judgements scale for Pairwise Comparisons

\begin{tabular}{ll}
\hline Verbal Judgments & Numerical Judgements \\
\hline Equally preferred & 1 \\
Equally to moderately & 2 \\
Moderately preferred & 3 \\
Moderately to strongly & 4 \\
Strongly preferred & 5 \\
Strongly tovery strongly & 6 \\
Very strongly preferred & 7 \\
Very strongly to extremely & 8 \\
Extremely preferred & 9 \\
\hline
\end{tabular}

Table 3: Table Format for Alternatives and Criteria

\begin{tabular}{lllllll}
\hline & \multicolumn{7}{l}{ Criteria } & & & \\
\cline { 2 - 6 } Alternatives & $\mathrm{C}_{1}$ & $\mathrm{C}_{2}$ & $\ldots$ & $\mathrm{C}_{j}$ & $\ldots$ & $\mathrm{C}_{m}$ \\
\hline $\mathrm{A}_{1}$ & $\mathrm{P}_{11}$ & $\mathrm{P}_{12}$ & $\ldots$ & $\mathrm{P}_{1 j}$ & $\ldots$ & $\mathrm{P}_{1 \mathrm{~m}}$ \\
$\mathrm{~A}_{2}$ & $\mathrm{P}_{21}$ & $\mathrm{P}_{22}$ & $\ldots$ & $\mathrm{P}_{2 j}$ & $\ldots$ & $\mathrm{P}_{2 m}$ \\
$\ldots$ & $\ldots$ & $\ldots$ & $\ldots$ & $\ldots$ & $\ldots$ & \\
$\mathrm{A}_{\mathrm{i}}$ & $\mathrm{P}_{\mathrm{il}}$ & $\mathrm{P}_{\mathrm{i} 2}$ & $\ldots$ & $\mathrm{P}_{\mathrm{ij}}$ & $\ldots$ & $\mathrm{P}_{\mathrm{im}}$ \\
$\ldots$ & $\ldots$ & $\ldots$ & $\ldots$ & & $\ldots$ & $\ldots$ \\
$\mathrm{A}_{n}$ & $\mathrm{P}_{n 1}$ & $\mathrm{P}_{n 3}$ & $\ldots$ & $\mathrm{P}_{n j}$ & $\ldots$ & $\mathrm{P}_{n m}$ \\
\hline
\end{tabular}

\subsection{Determination of Alternatives}

The choice of alternatives was considered not only considered from the angle of potential investors who are mainly interested in financial aspect of the projects; contributions were also obtained from experts in the oil and gas sector.

Table 4: Alternatives used for gas monetization projects

\begin{tabular}{ll}
\hline Project ID & Alternatives (0ptions) \\
\hline $\mathrm{OP}_{1}$ & Gas-to-Products (GTP) \\
& $-\quad$ Gas to Liquids (GTL) \\
& $-\quad$ Methanol, methanol-to-olefins (MTO) \\
& $-\quad$ Ammonia/Fertilizers \\
$\mathrm{OP}_{2}$ & Energy (Power generation) \\
$\mathrm{OP}_{3}$ & Export (Gas to pipeline) \\
$\mathrm{OP}_{4}$ & Petrochemicals \\
\hline
\end{tabular}

\subsection{Selection of Criteria}

The first step in the selection of gas monetization projects is the determination of criteria or factors. A criterion is a basis for a decision that can be measured and evaluated [8]. The criteria were drawn from extensive discussions with experts in the oil and gas sector, this gave rise to the following; (1) Project economics (rate of return and profitability index; (2) Access to technology; (3) Market demands; (4) The quantity of gas consumed over the expected project life; (5) Employment generation; (6) Social and environmental impact; (7) Transportation infrastructure (road, river etc.); (8) Political considerations.
https://doi.org/10.47001/IRJIET/2020.408004

Table 5: Criteria used for the selection of gas monetization projects

\begin{tabular}{lll}
\hline Reference & Criteria & Description of Criteria \\
\hline C1 & Economics & Project economics (rate of return and profitability index) \\
C2 & Technology & Access to technology \\
C3 & Demand & Market demands \\
C4 & Consumption & Quantity of gas consumed over the expected project life \\
C5 & Transportation & Transportation infrastructure (road, river etc) \\
C6 & Employment & Employment generation \\
C7 & Socio-environmental & Social and environmental impact \\
C8 & Politics & Political considerations \\
\hline
\end{tabular}

\subsection{Participation of Experts and Stakeholders}

The identification of relevant stakeholders (i.e. key players) is crucial in the selection of economical, environmentally sensitive projects. Stakeholders in this context thus refers to those that will be directly affected by the projects when in operation, the Due to the involvement of varied cadre of people in the decision-making process, a decision tool such as AHP is designed to cope with both the rational and intuitive in selecting the most preferred from.

The quantitative aspect of the scale was used to translate the judgment values for the method which, afterwards, were reconverted into mathematical values and normalized [5].

\subsection{Check for Consistency}

In order to check for redundancy in the pairwise comparison, the consistency index (CI) is used as given by

$$
C I=\frac{\lambda_{\max }-n}{n-1}
$$

The consistency ratio (CR) is applied to ascertain if the calculations are adequately consistent and it is the ratio of $\mathrm{CI}$ and the random consistency index $\left(\mathrm{CI}^{*}\right)$

$$
C R=\frac{C I}{C I^{*}}
$$

\section{RESULTS AND DISCUSSIONS}
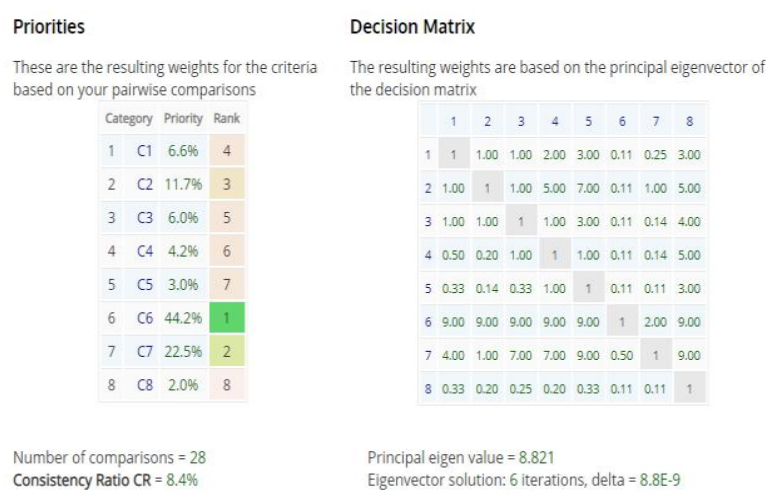
ISSN (online): 2581-3048

Volume 4, Issue 8, pp 20-24, August-2020 https://doi.org/10.47001/IRJIET/2020.408004

3.1 Project Economics

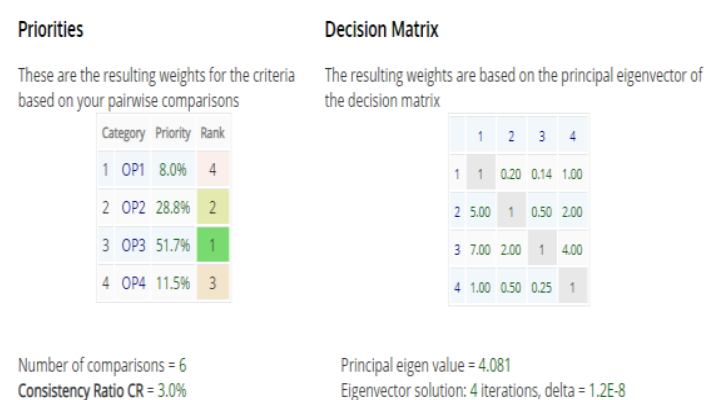

3.2 Technology Accessibility

$$
\begin{aligned}
& \text { Priorities } \\
& \text { These are the resulting weights for the criteria } \\
& \text { based on your pairwise comparisons } \\
& \qquad \begin{array}{llll|l|}
\text { Category Priority Rank } \\
11 & \text { OP1 } & 4.44 \% & 4 \\
\hline 2 & 0 P 2 & 30.7 \% & 2 \\
\hline 3 & O P 3 & 43.4 \% & 1 \\
\hline 4 & O P 4 & 21.6 \% & 3
\end{array}
\end{aligned}
$$

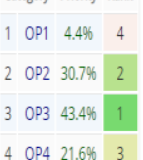

Number of comparisons $=6$

Consistency Ratio $C R=3.8 \%$

\subsection{Market Demands}

\section{Decision Matrix}

The resulting weights are based on the principal eigenvector of the decision matrix

$$
\begin{array}{|c|c|c|c|c|}
\hline 1 & 2 & 3 & 4 \\
\hline 1 & 1 & 0.14 & 0.11 & 0.20 \\
\hline 2 & 7.00 & 1 & 1.00 & 1.00 \\
\hline 3 & 9.00 & 1.00 & 1 & 3.00 \\
\hline 4 & 5.00 & 1.00 & 0.33 & 1 \\
\hline
\end{array}
$$

Principal eigen value $=4.105$
Number of comparisons $=6 \quad$ Principal eigen value $=4.105$ Consistency Ratio CR $=3.8 \%$
Principal eigen value $=4.105$
Eigenvector solution: 4 iterations, delta $=3.1$ E-8

3.4 Quantity of Gas Consumed

$$
\begin{aligned}
& \text { Priorities } \\
& \text { These are the resulting weights for the criteria } \\
& \text { based on your pairwise comparisons } \\
& \qquad \begin{array}{lll|l|}
\text { Category Priority Rank } \\
1 & \text { OP1 } & 12.5 \% & 3 \\
\hline 2 & \text { OP2 } & 4.2 \% & 4 \\
\hline 3 & \text { OP3 } & 31.4 \% & 2 \\
\hline 4 & \text { OP4 } & 51.996 & 1 \\
\hline
\end{array}
\end{aligned}
$$

\begin{tabular}{|c|c|c|c|c|c|}
\hline Priorities & & Decision Matrix & & & \\
\hline $\begin{array}{l}\text { These are the resulting weights } \\
\text { based on your pairwise compar }\end{array}$ & $\begin{array}{l}\text { Its for the criteria } \\
\text { Jarisons }\end{array}$ & $\begin{array}{l}\text { The resulting weights are ba } \\
\text { the decision matrix }\end{array}$ & asedo & on the & principal eigenvector of \\
\hline Category Priority $P$ & Rank & 1 & 2 & 3 & 4 \\
\hline 1 OP1 $14.0 \%$ & 2 & 11 & & & 200 \\
\hline 2 OP2 $64.3 \%$ & 1 & 25.00 & 1 & 5.00 & 7.00 \\
\hline 3 OP3 $14,0 \%$ & 2 & 31.00 & & 1 & 2000 \\
\hline $40 P 47.7 \%$ & 4 & 40.50 & 0.14 & 0.50 & 1 \\
\hline Number of comparisons $=6$ & & Principal eigen value $=4.0$ & & & \\
\hline
\end{tabular}

Decision Matrix

The resulting weights are based on the principal eigenvector of the decision matrix

$$
\begin{array}{|c|c|c|c|c|}
\hline 1 & 2 & 3 & 4 \\
\hline 1 & 1 & 5.00 & 0.33 & 0.17 \\
\hline 2 & 0.20 & 1 & 0.11 & 0.14 \\
\hline 3 & 3.00 & 9.00 & 1 & 0.50 \\
\hline 4 & 6.00 & 7.00 & 2.00 & 1 \\
\hline
\end{array}
$$

Principal eigen value $=4.211$

Eigenvector solution: 6 iterations, delta $=8.7 \mathrm{E}-9$

\subsection{Transportation Infrastructure}

3.6 Employment Generation

$$
\begin{aligned}
& \text { Priorities } \\
& \text { These are the resulting weights for the criteria } \\
& \text { based on your pairwise comparisons } \\
& \qquad \begin{array}{llll|}
\text { Cattegory Priority Rank } \\
1 & \text { OP1 } & 56.2 \% & 1 \\
\hline 2 & \text { OP2 } & 10.0 \% & 4 \\
\hline 3 & \text { OP3 } & 10.8 \% & 3 \\
\hline 4 & \text { OP4 } & 23.0 \% 6 & 2 \\
\hline
\end{array}
\end{aligned}
$$

Number of comparisons $=6$ Consistency Ratio $C R=1.1 \%$
Decision Matrix

The resulting weights are based on the principal eigenvector of the decision matrix

$$
\begin{array}{|l|c|c|c|c|}
\hline 1 & 7.00 & 5.00 & 2.00 \\
\hline 2 & 0.14 & 1 & 1.00 & 0.50 \\
\hline 3 & 0.20 & 1.00 & 1 & 0.50 \\
\hline 4 & 0.50 & 200 & 200 & 1 \\
\hline
\end{array}
$$

Principal eigen value $=4.030$

Eigenvector solution: 4 iterations, delta $=3.8 E-10$

\subsection{Social and Environmental Impact}

$$
\begin{aligned}
& \text { Priorities } \\
& \text { These are the resulting weights for the } \\
& \text { based on your pairwise comparisons } \\
& \qquad \begin{array}{|l|l|l|l|}
\text { Category } & \text { Priority } \\
\hline 1 & \text { OP1 } & 8.6 \% & 3 \\
\hline 2 & \text { OP2 } & 27.1 \% & 2 \\
\hline 3 & \text { OP3 } & 58.2 \% & 1 \\
\hline 4 & \text { OP4 } & 6.1 \% & 4 \\
\hline
\end{array}
\end{aligned}
$$

These are the resulting weights for the criteria

Number of comparisons $=6$ Consistency Ratio $C R=8.8 \%$
Decision Matrix

The resulting weights are based on the principal eigenvector of the decision matrix

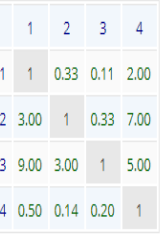

Principal eigen value $=4.241$ Eigenvector solution: 6 iterations, delta $=1.5 \mathrm{E}-8$

\subsection{Political Consideration}

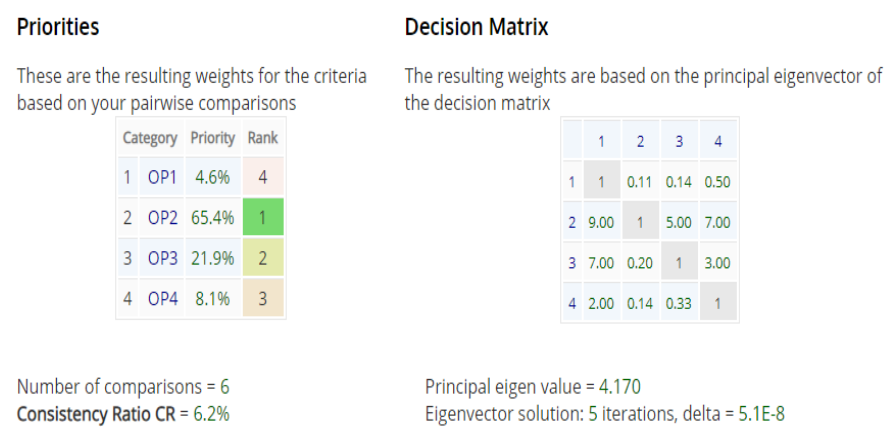




\subsection{Sensitivity Analysis}

Before a project is chosen, sensitivity analysis is carried out to determine how sensitive the selections are to alteration in the weights of criteria. It is dependent on the error in the input data and it is normally applied in situations of uncertainties in terms of the importance of various factors.

There are a number of catalytic processes involved in the synthesizing of gas into fuels and chemicals. Due to the high demand for environmental suitable fuel to meet the demand for energy globally, much research is now geared into processes such as Fischer-Tropsch (FT). The Fischer-Tropsch process or Fischer-Tropsch synthesis is a set of catalytic processes for converting synthesis gas (syngas, carbon monoxide hydrogen and/or other gases mixture) into liquid hydrocarbons. [9].

\section{CONCLUSION}

The focus of this paper was to choose the most preferred Natural gas monetization projects based on is the weights of the criteria increasingly gaining relevance as an economic and political mainstay not only for Nigeria but for the African sub region in general Natural gas is more expensive to transport in comparison to oil. The most convenient option to transport gas over large distances is by pipelines. The utilization of natural gas in Nigeria will help to reduce gas flaring and the emission of greenhouse gas.

\section{REFERENCES}

[1] C. Marcilly, "Present status and future trends in catalysis for refining and petrochemicals," Journal of Catalysis, vol. 216, pp. 47-62, 2003.

[2] OPEC, "Annual Statistical Bulletin," Organization of the Petroleum Exporting Countries, Vienna, Austria, 2013.

[3] F. I. Ibitoye, "Ending Natural Gas Flaring in Nigeria's Oil Fields," Journal of Sustainable Development, vol. 7, no. 3, pp. 13-22, 2014.

[4] A. Farkas, "The Use of the AHP in Civil Engineering Projects," Budapest, Hungary, 2010.

[5] L. Gomes, L. Rangel and F. Maranhão, "Multicriteria analysis of natural gas destination in Brazil: An application of the TODIM method," Mathematical and Computer Modelling, vol. 50, no. 1-2, pp. 92-100, 2009.

[6] C. Nwaoha and D. Wood, "A review of the utilization and monetization of Nigeria's natural gas resources: Current realities," Journal of Natural Gas Science and Engineering, vol. 18, pp. 412-432, 2014.

[7] T. L. Saaty, The Analytic Hierarchy Process: Planning, Priority Setting and Resource Allocation, New York: McGraw-Hill, 1980.

[8] J. R. Eastman, W. Jin, P. A. K. Kyem and J. Toledano, "Raster procedures for multi-criteria/multiobjective decisions," Photogrammetry and Remote Sensing, vol. 61, no. 5, pp. 539-547, 1995.

[9] J. Hu, F. Yu and Y. Lu, "Application of Fischer-Tropsch Synthesis in Biomass to Liquid Conversion," Catalysts, vol. 2, pp. 303-326, 2012.

[10] J. Wan, G. Qi, Z. Zeng and S. Sun, "The Application of AHP in Oil and Gas Pipeline Route Selection," in 19th International Conference on Geoinformatics, Shanghai, China, 2011.

[11] T. L. Saaty and L. G. Vargas, Models, Methods, Concepts \& Applications of Analytic Hierarchy Process, Second ed., New York: Springer, 2012.

[12] R. Ramanathan, "A note on the use of the analytic hierarchy process for environmental impact assessment," Journal of Environmental Management, vol. 63, pp. 27$35,2001$.

\section{Citation of this Article:}

Omo-Irabor Omoleomo O., Omo-Irabor Imuetiyan E., Ogala Jude E., Emudianughe, Juliet E., “A Multicriteria Decision Tool for Prioritizing Gas Monetization Projects in Nigeria" Published in International Research Journal of Innovations in Engineering and Technology - IRJIET, Volume 4, Issue 8, pp 20-24, August 2020. https://doi.org/10.47001/IRJIET/2020.408004 